\title{
Parental perceptions of the learner driver log book system in two Australian states
}

\author{
Dr Lyndel Bates ${ }^{a b}$ \\ L.Bates@griffith.edu.au
}

Professor Barry Watson ${ }^{\text {a }}$

B.Watson@qut.edu.au

Dr Mark King a

Mark.King@qut.edu.au

${ }^{a}$ Centre for Accident Research and Road Safety - Queensland (CARRS-Q), Queensland University of Technology

130 Victoria Park Road, Kelvin Grove, Qld, 4059, Australia

${ }^{\mathrm{b}}$ Current address: School of Criminology and Criminal Justice, Griffith University

176 Messines Ridge Road, Mt Gravatt, Qld, 4122, Australia 


\title{
Parental perceptions of the learner driver log book system in two Australian states
}

\begin{abstract}
Objective: While many jurisdictions internationally now require learner drivers to complete a specified number of hours of supervised driving practice before being able to drive unaccompanied, very few require learner drivers to complete a log book to record this practice and then present it to the licensing authority. Learner drivers in most Australian jurisdictions must complete a log book that records their practice thereby confirming to the licensing authority that they have met the mandated hours of practice requirement. These log books facilitate the management and enforcement of minimum supervised hours of driving requirements.
\end{abstract}

Method: Parents of learner drivers in two Australian states, Queensland and New South Wales, completed an online survey assessing a range of factors, including their perceptions of the accuracy of their child's learner log book and the effectiveness of the log book system.

Results: The study indicates that the large majority of parents believe that their child's learner log book is accurate. However, they generally report that the log book system is only moderately effective as a system to measure the number of hours of supervised practice a learner driver has completed.

Conclusions: The results of this study suggest the presence of a paradox with many parents possibly believing that others are not as diligent in the use of log books as they are or that the system is too open to misuse. Given that many parents report that their child's log book is accurate, this study has important implications for the development and ongoing monitoring of hours of practice requirements in graduated driver licensing systems.

\section{Keywords}

supervised driving, parental supervision, graduated driver licensing, learner licence, learner log book, supervised practice 


\section{Parental perceptions of the learner driver log book system in two Australian states}

\section{INTRODUCTION}

Individuals experience their highest crash risk immediately after gaining a driver's licence that allows unaccompanied driving, with this risk falling rapidly during the next few months and then falling more slowly for the next 18 months to two years (Lewis-Evans, 2010; Mayhew, Simpson, \& Pak, 2003; McCartt, Shabanova, \& Leaf, 2003; Williams, 2003). One countermeasure used to address the high crash risk of newly licensed drivers is graduated driver licensing (GDL) which focuses on reducing the crash risk for new drivers as a group rather than for individual drivers (Foss, 2007; McCartt, Teoh, Fields, Braitman, \& Hellinga, 2010; Shults, 2010). There are three stages in a GDL system - learner phase, intermediate stage (also known as a provisional or probationary licence in Australia) and full licence (Williams \& Mayhew, 2003). The learner phase allows the new driver to develop driving skills under the supervision of a more experienced driver (Mayhew, 2003), while an intermediate licence allows solo driving subject to restrictions (Preusser \& Leaf, 2003).

The learner phase is designed to allow new drivers the opportunity to gain practical driving experience with vehicle handling, the road environment and with the behaviour of other drivers (Foss, 2007). This phase recognises that individuals need to learn how to drive and to accumulate their initial

driving experience in lower risk situations with an experienced supervisor (Mayhew, 2003; Shults, 2010). While the learner phase is critical in a comprehensive GDL system (Bates, Watson, \& King, 2009a), it is important to note that supervised driving is inherently different from unaccompanied driving (Foss, 2007). Supervised driving is designed to effectively teach and allow the learner to accumulate experience as a driver.

Research examining the fatal crashes of 15 year olds in North America found that learners driving under supervision and in accordance with the conditions of their licence had comparatively few crashes. Those learners who did crash generally did so while unlicensed or in violation of the conditions of their 
licence (Williams, Preusser, Ferguson, \& Ulmer, 1997). More recent research from North Carolina that used semi-structured interviews with the parents of teenage learner drivers as well as in-vehicle cameras supports prior research indicating the low crash risk of learner drivers with none of the 52 teenage drivers participating in the study being involved in a collision during the 12 month learner licence stage (Goodwin, Foss, Margolis, \& Waller, 2010). Crash data from the Australian state of Victoria and New Zealand confirm that the learner licence stage is the safest for new drivers. Learner drivers in Victoria are involved in the least number of casualty crashes per month when compared with drivers that hold an intermediate or open licence (Cavallo, 2006). Learner drivers in New Zealand are involved in fewer fatal and injury crashes per 10,000 drivers per month when compared with drivers that hold an intermediate licence (Lewis-Evans, 2010).

A key factor within GDL systems is the level of support that parents provide (Jacobsohn, GarciaEspana, Durbin, Erkoboni, \& Winston, 2012; Mayhew, 2003; Williams \& Shults, 2010). Parents appear to be supportive of GDL programs (Brookland \& Begg, 2011; McKay, Coben, Larkin, \& Shaffer, 2008). Parents indicate that parents should have a strong involvement in the learning to drive process (Bates, 2012). Parents provide a role model for their children both before and once they commence learning to drive (Taubman-Ben-Ari, 2010, 2011) and they should therefore be encouraged to provide a good example to their children (Scott-Parker, Bates, Watson, King, \& Hyde, 2011; Scott-Parker, Watson, \& King, 2009; Scott-Parker, Watson, King, \& Hyde, 2012).

The support of parents is necessary in order for the majority of learner drivers to accrue sufficient driving experience given the often prohibitive cost of professional driving instruction (Bates, Watson, \& King, 2013; Harrison, 2004). Most parents do not appear to find the requirement for learner drivers to be supervised too inconvenient (Brookland \& Begg, 2011), although parents report that it is more difficult to find time to supervise learner drivers when compared with supervisors who are not parents (Bates, 2012). 
Some jurisdictions require learners to obtain a minimum number of supervised driving hours, with research suggesting this increases the amount of practice undertaken (Scott-Parker et al., 2011; Waller, Olk, \& Shope, 2000). These requirements in the United States of America vary from 20 hours in both Texas and Iowa to 65 hours in Pennsylvania (Insurance Institute for Highway Safety, 2012). Some Australian jurisdictions including Queensland and New South Wales require significantly higher amounts of supervised practice. Learner drivers in Queensland must record a minimum of 100 hours in a log book while those in New South Wales must record 120 hours (Scott-Parker et al., 2011; Senserrick, 2007, 2009). There appears to be little research basis for the selection of particular time requirements (Foss, 2007), although the Australian driver licensing authorities generally cite the work of Gregersen (eg. Gregersen et al., 2000) as the rationale for the higher amount of hours they require. The evidence from Gregersen's research suggests that 118 hours of supervised learning reduces post-licence crash rates for these drivers (Gregersen et al., 2000). While research suggests that learner drivers are able to obtain 50 hours of supervised driving (Bates, Watson, \& King, 2010) or record 100 hours of practice in a log book (Scott-Parker et al., 2011) when either of these are a requirement of the driver licensing system, there is little research regarding learner and parental perceptions of these requirements.

In Australia several states require the learner driver to complete and record the mandatory minimum number of hours of supervised practice in a log book, before attempting a practical driving test to obtain their provisional driving licence. The log book is a hard copy book that contains a table that the learner drivers and the supervisors complete to record the learner drivers' driving experiences. Learners and their supervisors are required to record the date, the licence plate of the vehicle, the start and finish times, locations and odometer readings as well as the name of the supervisor, their driver's licence number and state of issue, and the signature of the supervisor. Additionally, log books record whether the supervised driving was undertaken through a driving school or at night. Subtotals are calculated at the end of each page to identify the number of hours of practice completed thus far. While the specific processes vary between states in Australia, learner drivers in Queensland are required to submit their log book to the 
licensing authority that then assesses it prior to the learner being able to undertake their practical driving test to obtain a provisional driving licence. Once the licensing authority has assessed the log book, learner drivers are notified of the outcome and are then able to undertake the practical driving test (Queensland Department of Transport and Main Roads, 2013). Fines are imposed for false or misleading statements in the $\log$ book.

This contrasts to the system that operates in much of the United States of America where an honour system is in place in regards to the compulsory number of hours of practice prior to obtaining a provisional licence (Williams, 2007). Maryland is one state in the United States of America that requires a detailed log of the learner driver's hours of supervised practice. In other states such as Washington, Minnesota, South Carolina and Ohio, parents sign a form indicating that the learner driver has completed the required hours of practice (O'Brien, Foss, Goodwin, \& Masten, 2013).

Research with parents in Maryland, Washington, Minnesota, Ohio and South Carolina examined parental awareness of mandated driving requirements and how these requirements within their state were enforced. While there are differences between the five states, parental awareness of supervised driving requirements is relatively low (O'Brien et al., 2013). In Maryland, which requires a detailed driving log, 91 per cent of parents reported keeping a log. However, the number of parents that kept a log in the other four states within the study where it was not a required part of the licensing system was much lower.

In July 2007, Queensland and New South Wales both amended their graduated driving licensing systems. Amongst a range of changes, Queensland introduced and New South Wales amended the log book requirements. As noted earlier, in Queensland, learner drivers now need to record 100 hours of supervised practice. However, learners are able to record three hours in their log book for every one hour completed with a professional driving instructor up to 10 hours of practice (ie 30 hours in a log book). Additionally, 10 of the log book hours must be completed at night (Scott-Parker et al., 2011; Senserrick, 2009). Previously, there had been no minimum practice requirement and no compulsory log book, 
although a voluntary log book had been available for use. In New South Wales, learner drivers had previously been required to complete and record 50 hours of supervised practice in a log book (Bates et al., 2010). The amendments made in July 2007 increased the number of hours to 120 (Senserrick, 2007) with 20 of the log book hours in New South Wales required to be completed at night (Faulks \& Irwin, 2009; Senserrick, 2009). Learner drivers submit their log book to the relevant licensing authority for auditing prior to undertaking the practical driving test. Since the data for this study was collected learner drivers in New South Wales, like those in Queensland, are now able to record three hours of practice in their log book for every hour with a professional driving instructor up to $30 \log$ book hours. The required hours of practice in Queensland and New South Wales are significantly more than Western Australia where 25 hours of supervised practice is required to be recorded in a log book (Adams, 2005; Senserrick, 2009) and jurisdictions in the United States of America (Insurance Institute for Highway Safety, 2012).

Log books may offer a number of benefits including encouraging learner drivers and their instructors to better structure their driving experiences or to facilitate communication between private and professional instructors (Bates, Watson, \& King, 2008). However, the community consultation undertaken prior to the introduction of the changes to the Queensland GDL system indicated community concern that log books could be falsified (Solomon, King, \& Moore, 2006). Potentially this means that log books could provide an inaccurate record of practice undertaken, possibly defeating the purpose for introducing them.

There has been limited research that examines the system of learner log books with most of the existing research either using the log book to assess some other aspect of learner behaviour (Faulks, Irwin, \& Morphett, 2010) or focussing on the learner driver perspective in regard to the log book system. Previous research has examined the self-reported behaviour of novice drivers in relation to the completion of log books (Bates et al., 2008; Bates, Watson, \& King, 2009b; Bates et al., 2010; Scott-Parker et al., 2011). This research identified that log books tend not to be completed when they are a voluntary tool (Bates et al., 2008, 2010) with over two thirds of newly licensed drivers (67.7\%) in Queensland, under the 
former GDL system being unaware that a voluntary log book was available for use (Bates et al., 2009b). It is likely that log books may be more successful as a tool when they are either compulsory or supported by programs that encourage their use (Bates et al., 2010).

Even when log books are compulsory, learner drivers do not always use them appropriately. Drivers who had just obtained their provisional licence, under the former system in New South Wales, were asked how often they completed their log book as a learner. The results suggest that while they completed their log book most of the time, they did not always do so (Bates et al., 2008). Research on the new, post mid-2007 GDL system introduced in Queensland, identified that 83.4 per cent of participants reported that their log books were accurate. However, an additional 12.6 per cent of participants reported that they rounded their log book entries up and a further four per cent reported including extra hours in their log book which had not actually been undertaken (Scott-Parker et al., 2011).

It appears that parents are pivotal in the accumulation of hours in a log book (Scott-Parker et al., 2011). When providing supervision to their child to enable them to obtain driving practice, they are required to sign the log book as supervisor and thus confirm the driving practice was undertaken and the $\log$ book entry is accurate. However, research to date does not appear to have examined parental perceptions' of log book accuracy and the effectiveness of the log book system, as well as parental involvement in log book completion. This paper will address this gap by considering parental perceptions of the accuracy of their learner's log book and the effectiveness of the log book system in measuring the amount of supervised practice undertaken by a learner driver.

\section{METHOD}

Participants in this sample were parents who had supervised learner drivers in either of the Australian states of Queensland or New South Wales. They were recruited by delivering flyers to letter boxes and asking participants who had completed the survey to forward the survey link to other parents who they knew might have been interested in completing the study. Participation was limited to parents 
who had supervised a learner driver within the past 12 months. Participants completed an online survey regarding their self-reported experiences while supervising learner drivers.

Prior to completing the internet survey, participants were provided with information regarding the study on the initial screen of the survey. Consent was given by the participant when they submitted the internet survey. The recruitment method and internet survey received approval from the Queensland University of Technology Human Research Ethics Committee. The internet survey was open for completion between July 2009 and May 2010 and took approximately 15 to 20 minutes to complete. Participants could elect to provide their contact details at the conclusion of the survey in order to receive a \$20 shopping voucher to reimburse them for their time.

The survey collected a range of socio-demographic variables such as gender, age, marital status and income. A series of questions asked participants about the accuracy of their child's learner log book, whether they ever rounded up or down the hours recorded in the log book and the circumstances in which this occurred. Participants were asked to provide information about how often their child had asked them to record additional practice that had not been undertaken. All accuracy variables within this study refer to the accuracy of their own child's log book. Parents were also asked their opinion on the general effectiveness of the log book system using the question: Do you think the log book system is an effective way of measuring the number of hours of practice a learner has completed? Participants could respond to this question using a five point likert scale.

The data collected in this study was analysed using SPSS. The significance level $(a)$ was set at .05. Categorical data was analysed using non-parametric tests with either the phi $(\phi)$ coefficient for $2 \times 2$ tables or the Cramer's Phi $\left(\phi_{c}\right)$ coefficient for larger tables used to measure the strength of association between the variables. An adjusted standardised residual statistic was used as a post hoc test for the chisquare tests if required. 
Although data collected using a Likert scale are not strictly interval data, parametric methods were used to analyse these data. This enabled the use of more sophisticated techniques that would not have been possible using non-parametric tests. An adequate number of participants was used to ensure that the power of the multiple regression analysis was maintained. Generally speaking, this was at least 50 plus eight times the number of independent variables for the multiple correlation and at least 104 plus eight times the number of independent variables for individual predictors. This is considered appropriate for identifying medium effect sizes using a significance level of .05 with 80 per cent power (Tabachnick \& Fidell, 1996). Analysis of covariance (ANCOVA) analyses were used if it appeared a covariate could impact on the results. Etasquared $\left(\eta^{2}\right)$ was used to measure effect size in the ANCOVA analyses.

\section{RESULTS}

\section{Participants}

The sample consisted of 232 parents of learner drivers with 50 per cent of the sample from each state. Nearly two-thirds of the sample was female (62.5\%) and most were married (70.7\%). Most participants indicated that they were the primary supervisor of their learner driver (70.9\%).

Table 1 outlines the socio-demographic characteristics of the sample broken down by the state of residence. There were no differences between the participants from Queensland and New South Wales in terms of gender, marital status and whether they were the primary supervisor of the learner driver. However, participants from Queensland were more likely to indicate that their income was greater than $\$ 40,000$ a year when compared with those from New South Wales. Consequently, this variable was controlled for in subsequent analyses. There were no age differences identified between Queensland participants whose mean age was $44.09(s d=8.59)$, and those from New South Wales whose mean age was $45.74(s d=9.31, t(230)=-1.4, p=.163)$.

INSERT TABLE 1 ABOUT HERE 


\section{Amount of Practice Recorded in the Log Book}

Within the total sample, 94 per cent of participants indicated that they either recorded all of the practice or most of the practice that they provided in their learner's log book. Due to the limited number of participants that indicated they recorded no practice within their learner's log book, the categories of 'no practice' and 'some practice' were combined for the purposes of a chi-square analysis. As shown in Table A1 in the appendix, there was a significant difference between the two states with parents from New South Wales more likely to report that they recorded all the supervised practice that they provided their learner driver in the log book when compared to parents from Queensland $\left(X^{2}(2)=24.08, p<.001\right.$, $\left.\phi_{c}=.320\right)$.

\section{Log Book Accuracy}

Participants were asked to indicate on scale from 1 (not very accurate) to 5 (very accurate) the level of accuracy of their learner drivers' log book. As shown in Table A2 in the appendix, parents from both Queensland and New South Wales indicated that the log books were relatively accurate. However, an ANCOVA that controlled for income identified that there was a significant difference between the two states with participants from New South Wales $(M=4.33, s d=.72)$ more likely to indicate that the $\log$ book was accurate when compared to those from Queensland $(M=3.92, s d=1.00 ; F(1,231)=13.67, p$ $\left.<.001, \eta^{2}=.06\right)$. Two further ANCOVAs also indicated that parents from Queensland were more likely to round hours up (Qld: $M=2.36, s d=1.23$; NSW: $M=1.84, s d=.97 ; F(1,231)=12.43, p=.001, \eta^{2}=$ $.05)$ and down in the log book (Qld: $M=2.24, s d=1.26$; NSW: $M=1.53, s d=.78 ; F(1,229)=25.81, p$ $\left.<.001, \eta^{2}=.10\right)$, although this occurred infrequently in both states.

The survey included a question that asked parents how often their learner had asked them to record additional practice time in the log book that had not been undertaken. As shown in Table A2 in the appendix, this occurred infrequently in both states. However, it was more likely to occur in Queensland 
$(M=1.82, s d=1.18)$ than in New South Wales $\left(M=1.41, s d=.79 ; F(1,231)=10.09, p=.002, \eta^{2}=\right.$ $.04)$.

\section{Log Book Effectiveness}

Participants were asked to report, on a scale of 1 (not very effective) to 5 (very effective), how effective they believed the log book system was as a method of measuring the number of hours of supervised practice a learner driver had completed. As shown in Table 2, parents from both Queensland $(M=3.34, s d=1.20)$ and New South Wales $(M=3.30, s d=1.07)$ indicated a moderate level of effectiveness. There was no difference identified between the two states $F(1,231)=.02, p=.897, \eta^{2}=$ $.00)$, after controlling for income levels.

\section{INSERT TABLE 2 ABOUT HERE}

A hierarchical regression was conducted to examine the extent to which socio-demographic characteristics, supervision characteristics, and reported log book accuracy predicted participants' beliefs about the effectiveness of the log book as a system to measure the number of hours of a supervised driving a learner driver has undertaken. The hierarchical regression was used to assess the relative contribution of log book accuracy on perceptions of the effectiveness of the log book system after the contribution of socio-demographic variables and supervision characteristics had been considered. Therefore, socio-demographic variables were entered as step one, supervision characteristics as step two and log book accuracy as step three. The results are shown in Table A3 in the appendix.

The first $(F(5)=2.06, p=.07)$ and second steps in the hierarchical regression were not statistically significant $(F(7)=1.57, p=.15)$. The third step in the hierarchical regression was statistically significant $(F(11)=4.92, p<.001)$ with this step explaining an additional 15 per cent of the variance. Thus a large amount of variance in parental perceptions of the effectiveness of the log book system remains unexplained. 
The significant predictors in the model were state of residence $(\beta=-.16, p=.019)$, perceptions regarding the accuracy of the $\log$ book $(\beta=.24, p=.001)$, the reported frequency with which hours were rounded up $(\beta=-.18, p=.013)$ and the reported frequency which the learner driver asked for additional uncompleted time to be recorded $(\beta=-.13, p=.052)$. Therefore, it appears that participants from New South Wales, those who perceived their child's log book to be accurate, did not round hours up and did not include uncompleted practice in the log book were more likely to believe that the log book is an effective tool to measure the number of hours of practice a learner driver completes.

\section{Professional Driving Instructors}

One possible additional use of the learner driver log book is to communicate with other supervisors of the learner drivers, such as professional driving instructors. Participants whose learners also had lessons with a professional driving instructor were asked if they had read the learner log book to identify what the learner had done with the professional driving instructor. As shown in Table A4 in the Appendix, more than 70 per cent of parents in both Queensland and New South Wales reported using the $\log$ book for this purpose. There were no apparent differences between the two states in relation to this behaviour $\left(X^{2}(1)=.954, p=.329, \phi=-.069\right)$.

\section{DISCUSSION}

Previous research has considered the self-reported completion of log books by young novice drivers (Bates et al., 2008, 2009a, 2010; Scott-Parker et al., 2011). Additionally, O’Brien et al (2013) researched the perceptions of parents in five states in the USA regarding how the mandated number of hours for learner drivers was enforced. Given that, apart from the O'Brien et al study, there is limited research that has considered parental perceptions of the log book system, this paper fills an important gap in the literature. In particular, it considers parental perceptions of the accuracy of their child's log book and the effectiveness of a log book system in measuring the amount of supervised practice undertaken by their child. 
As shown in this study, the majority of parents report recording all or most of the driving practice undertaken while under their supervision. Given the high number of hours that had to be recorded in the learner log book at the time in both Queensland (100 hours) and New South Wales (120 hours), parents may want to ensure that their child records all legitimate practice occasions in their log book. This tends to suggest that most are aware of the requirement to undertake supervised driving practice on a learner licence and to record this practice in a log book. This supports, O'Brien et al's (2013) contention that, by requiring learner drivers to complete a log book of their hours of supervised driving practice, it facilitates parental awareness of the requirement to complete a set number of supervised driving hours while on a learner licence.

Prior to the modified GDL systems being introduced in Queensland and New South Wales in mid-2007, learners in Queensland were not required to undertake a minimum amount of supervised driving practice or to record this practice in a log book. While there was a voluntary log book available, very few learners were aware of its existence (Bates et al., 2010). In contrast, learners from New South Wales were required to complete, and record in a log book, 50 hours of supervised driving practice. Several results from the current study may reflect the fact that log books have been a required part of the driving licensing system for longer in New South Wales than Queensland. For instance, most parents from both Queensland and New South Wales reported that they believed their child's log book was accurate. However, those from New South Wales reported a higher level of accuracy. Given the more established nature of the log book in New South Wales, parents from that state may have had a greater confidence in the system. The findings of the current study are also consistent with research which has examined the experiences of learner drivers in Queensland with 84.3 per cent of the learner drivers participating in the study indicating that their log book was accurate (Scott-Parker et al., 2011).

Participants reported that they rounded the hours in the log book up or down infrequently, although it was more likely that participants from Queensland, when compared with those from New South Wales, would round the hours (both up and down) in the log book. Additionally, although it was on 
an infrequent basis, supervisors from Queensland indicated that their child asked them to record additional uncompleted time in their log book more frequently than those from New South Wales. This is consistent with a previous study that identified that only four per cent of novice drivers from Queensland reported including extra hours in their log book (Scott-Parker et al., 2011). As well as again reflecting the more established nature of log books in New South Wales, the results of the current study may indicate that parents from Queensland are more happy to approximately measure the 100 hours of supervised driving that their child must complete.

Despite reporting that their child's log book is generally accurate and that rounding up and down the recorded hours undertaken within the log book is infrequent, parents indicated that they perceived that the log book system was only moderately effective as a system to record the number of hours of supervised practice that a learner driver completes. This finding may reflect a belief among many parents that others are not as diligent in the way they use the log books or that they are too open to misuse. This apparent paradox may be a result of individuals not valuing the log book process. While completing a log book may not directly enhance novice driver safety, it can encourage, facilitate and enforce the component of GDL that require learner drivers to complete a minimum number of supervised hours of driving practice. The absence of positive feedback regarding the log book system may mean that the media focuses on the negative aspects which may undermine the log book system. Further research is required to investigate this scenario.

This study suggests that there are some variables that had limited value in predicting the perceived effectiveness of the log book system to measure the number of hours of supervised practice a learner driver has completed. This included whether the supervisor is the mother or father, a first time or more experienced supervisor, or a primary or supplementary supervisor. This lack of differences is consistent with the findings of earlier research. Prior research with parental supervisors from Queensland, suggests that the quality of supervision provided by both mothers and fathers is similar, although mothers provide more hours of supervised driving practice than fathers (Bates et al., 2013). 
Either way, the findings of this study suggest that further education is required for supervisors and novice drivers regarding the role and value of log books. In addition, changing the delivery platform of the log book system may help. Currently, paper log books are used to record the hours of supervised driving practice undertaken in both Queensland and New South Wales. Introducing the use of electronic $\log$ books may be one method to improve both the actual and perceived effectiveness of the log book system (Fitz-Walter, Tjondronegoro, \& Wyeth, 2012). Parents may believe that an electronic log book system is less likely to include uncompleted supervised driving time.

Log books may also help facilitate communication between the learner driver's various supervisors (Bates et al., 2008). This study found that some parents use the log book to identify the lessons undertaken with a professional driving instructor. This suggests that the log book could, in addition to recording the number of hours of supervised driving practice that a learner driver undertakes, potentially have an important secondary role as a communication tool between different driving supervisors. This may be more important in jurisdictions where there are a significant number of driving hours required. Further research with professional driving instructors is needed to investigate the communication facilitation aspects of learner log books.

While the use of self-report data may be considered a potential limitation of the research, the use of this type of data enabled the researchers to obtain information from the participants that would have been difficult to obtain by other means (such as parental perceptions of their child's log book and the log book system). A further potential limitation of this study is the convenience and snowball recruitment techniques used within this study. The use of these methods means it is not possible to identify the response rate and reduces the confidence with which these results can be generalised to the population. Additionally, a volunteer bias could be present within the study as those parents who participated may have a stronger interest in road safety than other parents. While the provision of a financial incentive for participation may have helped diversify the sample of the participants, it is likely that the sample does not reflect the population of supervising parents. Although it is not possible to predict how this has affected 
the results, it is feasible that the more involved parents completed the survey. Therefore, the results may overestimate how accurate parents believe the log books to be. Replicating this study with a probability sample would address a possible volunteer bias and overcome any limitations associated with the sampling process.

While this study provides information regarding parental self-reported perceptions of the accuracy of their child's log book and the effectiveness of the system as a whole, future research is needed to obtain a more detailed understanding of these perceptions. This future research could examine why parents believe that the log book system is not effective as a system to measure the number of supervised hours of driving practice that a learner driver completes, what type of support parents provide to their child to ensure that the log book is kept in an accurate manner, the characteristics of those parents who rounded hours in the log book up or down and why parents round hours up and down. Additionally, research is required to gain a more detailed understanding of how parents and their learner drivers accommodate the requirement to meet high levels of supervised practice and their perceptions of the fairness of this type of obligation.

This study focused on parental perceptions of the log book system. Given that, at least in jurisdictions that require 100 or 120 hours of supervised practice, non-parental supervisors play an important supervisory role in enabling learner drivers to accumulate sufficient log book hours (Bates, 2012), there is a need for further research to investigate the perceptions of this group regarding the log book system.

Log book systems provide a mechanism for learner drivers and their supervisors, including their parents, to record the amount of practice that a learner driver undertakes. Licensing authorities in Queensland and New South Wales also use the log book as evidence that the learner driver has met the mandated hours of practice requirement although perceptions relating to the extent that log books are audited by the licensing authorities remain unclear. Consequently, this is an issue requiring more 
investigation. Based on this study, it appears that the majority of parents report that the entries in their child's learner log book are accurate and that they engage in minimal rounding up or down of hours of practice. Moreover, these results applied to two jurisdictions that require 100 hours and 120 hours of practice, respectively, to be recorded.

The results of this study are important for jurisdictions that have mandated hours of practice requirements and are considering the best way to ensure that this practice is undertaken. While Australian jurisdictions require learners to record the amount of practice they undertake while driving on a learner licence in a log book, this is not the case for many other jurisdictions internationally. This may be because there is a perception that the self-recording of information in log books is not accurate. However, this study provides support for the introduction of log books in other jurisdictions in order to document the amount of practice that a learner driver completes. This supports the findings of previous research with learner drivers suggesting that while a small proportion of learner drivers may round up the hours recorded in the log book, and an even smaller proportion record hours that were not undertaken, there are benefits of introducing a log book system in order to facilitate, manage and enforce the mandated hours of practice requirement during the learner licence in GDL systems.

\section{ACKNOWLEDGEMENTS}

The authors acknowledge the financial assistance of the Queensland Motor Accident Insurance Commission and Queensland University of Technology's Institute for Health and Biomedical Innovation for this study. The authors also acknowledge the assistance of Mr Michael Bates and Ms Jenny Bennett in the recruitment of participants for this study. The authors appreciate the feedback provided by the anonymous reviewers as part of the peer review process.

\section{REFERENCES}

Adams, C. Probationary and non-probationary drivers' nighttime crashes in Western Australia, 19962000. J Safety Res. 2005;36: 33-37. 
Bates, L. The Experiences of Learner Drivers, Provisional Drivers and Supervisors with Graduated Driver Licensing in Two Australian Jurisdictions. (PhD), University of Technology, Brisbane; 2012.

Bates, L., Watson, B., \& King, M.. The structure of the learner licence affects the type of experiences novices gain during this phase: Examples from Queensland and New South Wales. J Aust Col Road Safety. 2008;19:4: 36-42.

Bates, L., Watson, B., \& King, M. Driving and licensing experiences of learner drivers in two Australian states prior to changes in the licensing laws. J Aust Col Road Safety. 2009a;20:3:51-55.

Bates, L., Watson, B., \& King, M. Factors influencing learner driver experiences. Canberra: Department of Infrastructure, Transport, Regional Development and Local Government; 2009b.

Bates, L., Watson, B., \& King, M. Required hours of practice for learner drivers: A comparison between two Australian jurisdictions. J Safety Res. 2010;41:93-97.

Bates, L., Watson, B., \& King, M. Mothers Vs Fathers As Learner Driver Supervisors: Time Commitment, Driving Activities And Perceptions Of Risk. Paper presented at the 2013 Australasian Road Safety Research, Policing \& Education Conference, Brisbane, Australia; 2013.

Brookland, R., \& Begg, D. J. Adolescent, and their parents, attitudes towards graduated driver licensing and subsequent risky driving and crashes in young adulthood. $J$ Safety Res. 2011;42:2:109-115.

Cavallo, A. Victoria's New Graduated Driver Licensing System Younger Driver Licensing: Tales from Near and Far. Brisbane: Centre for Accident Research and Road Safety - Queensland; 2006.

Faulks, I., \& Irwin, J. The Graduated Driver Licensing System in New South Wales. J Aust Col Road Safety. 2009;20:1:13-20.

Faulks, I., Irwin, J., \& Morphett, A. Enhanced training and structured lesson planning for young drivers in New South Wales. Paper presented at the 2010 Australasian Road Safety Research, Policing and Education Conference, Canberra, Australia; 2010. 
Fitz-Walter, Z., Tjondronegoro, D., \& Wyeth, P. Encouraging learners to drive using game elements and smartphones. Paper presented at the Proceedings of the 24th Australian Computer-Human Interaction Conference (OzCHI 2012), Melbourne, Australia; 2012.

Foss, R. Improving graduated driver licensing systems: A conceptual approach and its implications. $J$ Safety Res. 2007;38:2:185-192.

Goodwin, A. H., Foss, R., Margolis, L. H., \& Waller, M. Parents, teens and the learner stage of graduated driver licensing. Washington: AAA Foundation for Traffic Safety; 2010.

Gregersen, N. P., Berg, H.-Y., Engstrom, I., Nolen, S., Nyberg, A., \& Rimmo, P.-A. Sixteen years age limit for learner drivers in Sweden - An evaluation of safety effects. Accid Anal Prev. 2000;32: $25-35$.

Harrison, W. A. Investigation of the driving experience of a sample of Victorian learner drivers. Accid Anal Prev, 2004:36:885-891.

Insurance Institute for Highway Safety. Young driver licensing systems in the U.S. .Retrieved 18 September, 2012, from http://www.iihs.org/laws/graduatedlicenseintro.aspx; 2012.

Jacobsohn, L., Garcia-Espana, J., Durbin, D. R., Erkoboni, D., \& Winston, F. K. Adult-supervised practice driving for adolescent learners: The current state and directions for interventions. J Safety Res. 2012;43:1:21-28.

Lewis-Evans, B. Crash involvement during the different phases of the New Zealand Graduated Driver Licensing System (GDLS). J Safety Res. 2010;41:359-365.

Mayhew, D. The learner's permit. J Safety Res. 2003;34:35-43.

Mayhew, D., Simpson, H. M., \& Pak, A. Changes in collision rates among novice drivers during the first months of driving. Accid Anal Prev. 2003;35:5:683-691.

McCartt, A., Shabanova, V. I., \& Leaf, W. A. Driving experience, crashes and traffic citations of teenage beginning drivers. Accid Anal Prev. 2003;35:311-320.

McCartt, A., Teoh, E. R., Fields, M., Braitman, K. A., \& Hellinga, L. A. Graduated Licensing Laws and Fatal Crashes of Teenage Drivers: A National Study. Traffic Inj Prevent. 2010;11:3:240 - 248. 
McKay, M. P., Coben, J. H., Larkin, G. L., \& Shaffer, A. Attitudes of teenagers and their parents to Pennsylvania's graduated driver licensing system. Traffic Inj Prevent. 2008;9:3:217-223.

O'Brien, N., Foss, R., Goodwin, A., \& Masten, S. V. Supervised hours requirements in graduated driver licensing: Effectiveness and parental awareness. Accid Anal Prev. 2013;50:330-335.

Preusser, D., \& Leaf, W. A. Provisional license. J Safety Res. 2003;34, 45-49.

Queensland Department of Transport and Main Roads. Learner Licence. Retrieved 7 January 2014, from http://www.tmr.qld.gov.au/Licensing/Learning-to-drive/For-the-learner/Learnerlogbook.aspx\#false; 2013.

Scott-Parker, B., Bates, L., Watson, B., King, M., \& Hyde, M. The impact of changes to the graduated driver licensing program in Queensland, Australia on the experiences of learner drivers. Accid Anal Prev. 2011;43:1301-1308.

Scott-Parker, B., Watson, B., \& King, M. Understanding the psychosocial factors influencing the risky behaviour of young drivers. Transp Res Part F: Traffic Psychol Behav. 2009;12:470-482.

Scott-Parker, B., Watson, B., King, M., \& Hyde, M. (2012). 'They're lunatics on the road': Exploring the normative influences of parents, friends, and police on young novices' risky driving decisions. Saf Sci. 50;1917-1928.

Senserrick, T. Recent developments in young driver education, training and licensing in Australia. $J$ Safety Res. 2007;38:2:237-244.

Senserrick, T. Australian Graduated Driver Licensing Systems. J Aust Col Road Safety. 2009;20:1:20-26.

Shults, R. A. Foreword to 'Graduated driver licensing research, 2007-present: A review and commentary'. J Safety Res. 2010;41:75.

Solomon, G., King, M., \& Moore, R. Queensland young driver community engagement process. Paper presented at the 2006 Australasian Road Safety Research, Policing and Education Conference, Surfers Paradise, Australia; 2006.

Tabachnick, B., \& Fidell, L. Using multivariate statistics (3rd ed.). New York: HarperCollins College Publishers; 1996. 
Taubman-Ben-Ari, O. Attitudes toward accompanied driving: The views of teens and their parents. Transp Res Part F: Traffic Psychol Behav. 2010;13:269-276.

Taubman-Ben-Ari, O. The contribution of perceived parental and familial characteristics to attitudes toward accompanied driving among young drivers. Accid Anal Prev. 2011;43:1720-1729.

Waller, P. F., Olk, M. L., \& Shope, J. T. Parental views of and experience with Michigan's graduated licensing program. J Safety Res. 2000;31:1:9-15.

Williams, A. Teenage drivers: Patterns of risk. J Safety Res. 2003;34:5-15.

Williams, A. Contribution of the components of graduated licensing to crash reductions. J Safety Res. 2007;38:2:177-184.

Williams, A., \& Mayhew, D. Graduated Licensing: A Blueprint for North America. Arlington: Insurance Institute for Highway Safety; 2003.

Williams, A., Preusser, D., Ferguson, S. A., \& Ulmer, R. Analysis of the fatal crash involvements of 15year-old drivers. J Safety Res. 1997;28:1: 49-54.

Williams, A., \& Shults, R. A. Graduated Driver Licensing Research, 2007-Present: A Review and Commentary. J Safety Res. 2010;41:77-84. 
Table 1 Sample characteristics by state of residence

\begin{tabular}{|c|c|c|c|c|}
\hline Characteristic & $\begin{array}{c}\text { Qld } \\
n(\%)\end{array}$ & $\begin{array}{l}\text { NSW } \\
n(\%)\end{array}$ & $\begin{array}{l}\text { Total } \\
n(\%)\end{array}$ & Statistical level \\
\hline Gender & $n=116$ & $n=116$ & $N=232$ & \\
\hline Male & $42(36.2)$ & $45(38.8)$ & 87 (37.5) & $X^{2}(1)=.17, p=.684$ \\
\hline Female & $74(63.8)$ & $71(61.2)$ & $145(62.5)$ & $\phi=-.027$ \\
\hline Marital status & $n=116$ & $n=116$ & $N=232$ & \\
\hline $\begin{array}{l}\text { Single } \\
\text { Married } \\
\text { Have a partner } \\
\text { Previously } \\
\text { married }\end{array}$ & $\begin{array}{c}12(10.3) \\
85(73.3) \\
10(8.6) \\
9(7.8)\end{array}$ & $\begin{array}{c}11(9.5) \\
79(68.1) \\
13(11.2) \\
13(11.2)\end{array}$ & $\begin{array}{c}23(9.9) \\
164(70.7) \\
23(9.9) \\
22(9.5)\end{array}$ & $\begin{array}{l}X^{2}(3)=1.38, p=.710 \\
\phi_{c}=.08\end{array}$ \\
\hline Income & $n=116$ & $n=116$ & $N=232$ & \\
\hline $\begin{array}{l}\$ 40,000 \text { or less } \\
\$ 40,001 \text { or more }\end{array}$ & $\begin{array}{l}32(27.6) \\
84(72.4)\end{array}$ & $\begin{array}{l}51(44) \\
65(56)\end{array}$ & $\begin{array}{c}83(35.8) \\
149(64.2)\end{array}$ & $\begin{array}{l}X^{2}(1)=6.77, p=.009 \\
\phi=-.171\end{array}$ \\
\hline $\begin{array}{l}\text { Primary } \\
\text { supervisor }\end{array}$ & $n=116$ & $n=114$ & $N=230$ & \\
\hline $\begin{array}{l}\text { Yes } \\
\text { No }\end{array}$ & $\begin{array}{l}82(70.7) \\
34(29.3)\end{array}$ & $\begin{array}{l}81(71.1) \\
33(28.9)\end{array}$ & $\begin{array}{c}163(70.9) \\
67(29.1)\end{array}$ & $\begin{array}{l}X^{2}(1)=.004, p=.952 \\
\phi=-.004\end{array}$ \\
\hline Age & $\begin{array}{c}M=44.09 \\
s d=8.59\end{array}$ & $\begin{array}{c}M=45.74 \\
s d=9.31\end{array}$ & $\begin{array}{c}M=44.92 \\
s d=8.98\end{array}$ & $t(230)=-1.4, p=.163$ \\
\hline
\end{tabular}


Table 2 Log book effectiveness, comparison between Queensland and New South Wales

\begin{tabular}{lccccc}
\hline \multicolumn{1}{c}{ Log book effectiveness } & $\boldsymbol{M}$ & $\boldsymbol{s} \boldsymbol{d}$ & $\boldsymbol{F}^{\boldsymbol{l}}$ & $\boldsymbol{d} \boldsymbol{f}$ & $\begin{array}{c}\text { Statistical } \\
\text { level }\end{array}$ \\
\hline Log book system effective $^{2}$ & & & & & \\
& & & & & \\
Queensland $(n=116)$ & 3.34 & 1.20 & .02 & 1,231 & $p=.897$, \\
New South Wales $(n=116)$ & 3.30 & 1.07 & & & $\eta^{2}=.00$ \\
\hline
\end{tabular}

\footnotetext{
${ }^{1}$ The ANCOVA controlled for income.

${ }^{2}$ Measured on a 5 point scale from 1 (not very effective) to 5 (very effective).
} 